\title{
Service Users' Involvement and Engagement in Interprofessional Care
}

\author{
Bachchu Kailash Kaini ${ }^{1}$ \\ 'Queen Elizabeth Hospital, Stadium Road, Woolwich, London, SE18 4QH, UK.
}

\section{ABSTRACT}

Interprofessional care is joint working between health care professionals by pooling their skills, knowledge and expertise, to make joint decisions and learn from each other for the benefits of service users and healthcare professionals. Service users involvement is considered as one of the important aspects of planning, management and decision making process in the delivery of health care to service users. Service users' involvement is not the same as public involvement and partnership arrangements in health care. The active involvement and engagement of service users in health care positively contributes to improve quality of care, to promote better health and to shape the future of health services. Service users are always at the centre of health care professionals' values, work ethics and roles. Moreover, service users centred interprofessional team collaboration is very important to deliver effective health services.

Keywords: interprofessional; service users; health care; benefits; collaboration.

\section{INTRODUCTION}

Interprofessional Care: Interprofessional care involves joint working and interactions between health care professionals. It is a collaborative working in which health care professionals share a common purpose of developing mutually negotiated goals, which are achieved through an agreed care plan, management and procedures. ${ }^{1,2,3}$ For interprofessional care to happen in practice, health care professionals pool their knowledge, skills and expertise ${ }^{4}$ and make a joint decision based upon the shared professional view points ${ }^{5}$.

Finch $^{6}$ defines interprofessional as 'a professional's skills, knowledge and roles that are adapted to fit in with other professions'. Interprofessional care requires health care professionals from different professions and organisations to work together to offer the best health service to the benefit of the service user. Interprofessional care is the process for providing the best health services to service users and achieve the optimal desired outcomes and service users' satisfaction. The Health Force Ontario ${ }^{7}$ defines interprofessional care in its report 'Interprofessional Care: A Blueprint for Action in Ontario' and states that it is 'the provision of comprehensive health services to patients by multiple health caregivers, who work collaboratively to deliver quality care within and across settings'.

Service Users: Different terms are used to people who use services, such as 'patients', 'lay person', 'survivor', 'service users', 'consumer', 'carer', 'user', 'partners' and 'client'. ${ }^{8}$ In varying situations, a different term might be used. Within any context, 'patient' may like to be called as consumer, others client or service user. It is not that one word is necessarily right and another is wrong, but the term 'service user' in this paper is used to represent all of the terms mentioned above. The health service is one of the biggest service sectors and has many facets. There are various types of service users with various needs and complexities. Therefore, the term 'service user' is used to denote those who receive health services.

Correspondence: Bachchu Kailash Kaini, Queen Elizabeth Hospital, Stadium Road, Woolwich, London, SE18 4QH, UK. Email: bkaini@nhs.net 
Health service providers' and the governments' widespread commitment to involving service users and public in their own health care and in the planning, review and delivery of health care has become a key element of policy explicitly set out within many of the recent legislative and policy documents. Safe and effective working relationships and respectful inclusion of service users are characteristic of interprofessional collaborative practice. ${ }^{5}$ Interprofessional care envisions service users as active members of the health care team and confident in the health care system's ability to meet their needs.$^{9}$

According to House of Commons of the United Kingdom, Health Committee ${ }^{10}$ report, Patient and Public Involvement in the National Health Service' service users involvement is not the same as public involvement in health service planning, management and delivery. Service users' involvement is more about their health such as participation in treatment decisions with clinicians, choice over service providers and giving feedback and views on the services they receive. Public involvement is mostly for health service planning, policy development and management such as giving their opining about service redesign, service relocation, voting for board members, active involvement in consultation for policy formation etc.

Leathard $^{3}$ has differentiated between the two terms 'service user involvement' and 'partnership' arrangements. Leathard ${ }^{3}$ suggests that service user's involvement in health care set up is a more medicalised approach based on complex arrangements where as a partnership arrangement is working closely together across health and social services and user agencies which might better suit their context and needs. Service users' engagement in health and social care has been viewed as a positive move for the better delivery of

health care.

\section{ROLE OF SERVICE USERS}

Service user involvement is increasingly becoming accepted by health service planners, service providers and service users as a valid concept, in which the need to listen and act on the views of patients and the public is an integral part of the planning and delivery of health care. Service user involvement is the opportunity for individuals who may be, or have been patients, to play an active role in decisions made about their treatment and care and to be included in debates about planning decisions for local organisations and the delivery of health services. As service users, they expect their health care to be provided by various health care professionals who respect service users and the health care choices they make. Service users seek to know their health experience and are prepared to work with them across various settings to combine their knowledge and skills to meet their health goals. ${ }^{11}$

The Postgraduate Medical Education Training Board in the United Kingdom (PMETB) ${ }^{12}$ asserts that the patienthealth care professionals' relationship is central to health care service users' perceptions of the care that they receive and it will constantly be redefined by changes in society, demographics and the political agenda in which the relationship operates. In the current climate, health care service users are more actively involved in their care and the health care delivery system. They are the best and most reliable sources of information. Their active involvement and engagement positively contributes to improve quality of care, to promote better health and to shape the future of health services.

Overall expectations of public services have risen in the last two decades, driven by higher rates of education, increased incomes, a more sophisticated mobile population, use of the internet and less deference to expert opinion. ${ }^{13}$ Service users play a very important role in planning and the delivery of their own care. In the health service, service users' expectations are ever increasing. Health service users want better and faster access to services. Furthermore, they want health services closer to their home. Research suggests that service users view the health sector as powerful and difficult to change and that there is some doubt about participation based on previous experiences, rather service users believe that by organising collectively, they have the best chance of effecting. ${ }^{14}$ It is also emphasised that service users' participation requires power sharing, but that those in the system find it hard to give up control.

\section{ROLE OF HEALTH CARE PROFESSIONALS}

The inclusion of service users and carers into the interprofessional care team is seen as essential if different forms of organisational control are to be avoided. Hornby and Atkins ${ }^{15}$ state that service users can constrain the exercise of professional discretion by making interprofessional care team members subordinate to one health care professional group or to the culture generated by the interprofessional care team.

Understanding the various viewpoints (family, community, social, physical and psychological aspects) of service users is an important criterion of assessment and judgement while offering services to service users by health care professionals. If service users' are engaged in their care plans and treatment 
decisions, it helps health care professionals to create a complete picture of service users by evaluating all their perspectives. In addition to the service users, their carers, family members and friends may become part of the health care team in varying degrees. ${ }^{16}$ They often help make major decisions in the care planning and management such as discharge planning and offer many other emotional and physical supports.

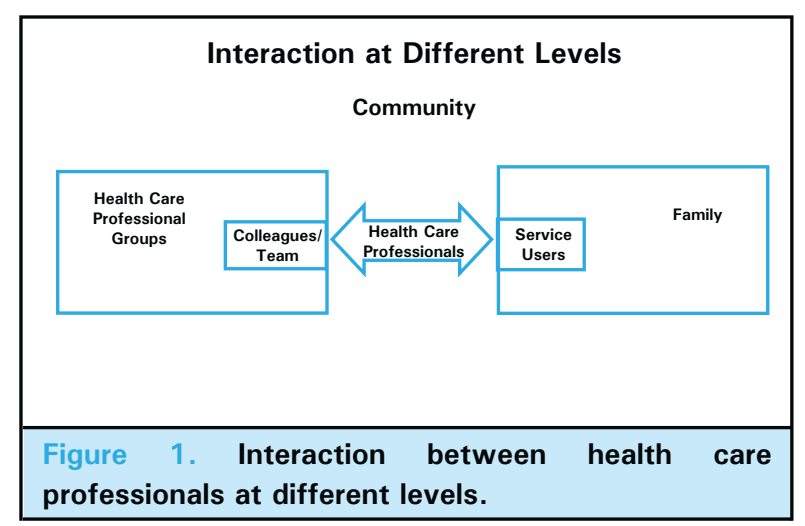

If health care professionals are to succeed in the objectives of involving service users in decision making, they need to empower service users for effective delivery of health services. ${ }^{3}$ In interprofessional team collaboration, service users empowerment can be defined as an individual being an active member of their disease, care plan and management team. Service user empowerment does not only include the ability of the service user to take decisions and be an active member in their care, it also consists of their education on the topic of their care or issues. Service users benefit from inclusion as members of the service delivery team and they need to be assured that their personal circumstances, feelings and preferences are acknowledged and acted upon. ${ }^{17}$ Service users' involvement in health care delivery improves informed consent and compliance for their treatment plan, management and care.

Interprofessional team collaboration in health and social care has been perceived positively by service users. Some service users understand the pressures behind interprofessional team collaboration while others fear that communication between professionals may lead to unwanted and unnecessary attention. ${ }^{18}$ Various other literatures identify many benefits from service users' involvement at both an individual and organisational levels such as better clinical treatment outcomes, more appropriate and relevant services, increased legitimacy and credibility of decision making, increased sense of dignity and self-worth and improved service user satisfaction. ${ }^{14,19-21}$

Supporting service users in the decision making process is not easy to achieve as there is a power imbalance between health care professionals and service users in the actual health service delivery process. ${ }^{3}$ Service users are always at the centre of health care professionals' values, work ethics and roles. Health care professionals join hands and work together in order to keep service users safe and to provide the best possible care and services. Health care professionals are working in an environment of changing health service users expectations, service need and government regulation. Therefore, they need to find new and innovative ways of responding to these current and future challenges. Service users - doctor interactions have evolved over time and will continue. ${ }^{12}$ In the early days of the health services the relationship between the patient and health care professionals was conceptualised in a paternalistic manner. Service users in health care were seen as passive recipients of care, and health care professionals were seen as possessing a superior professional knowledge. ${ }^{22}$

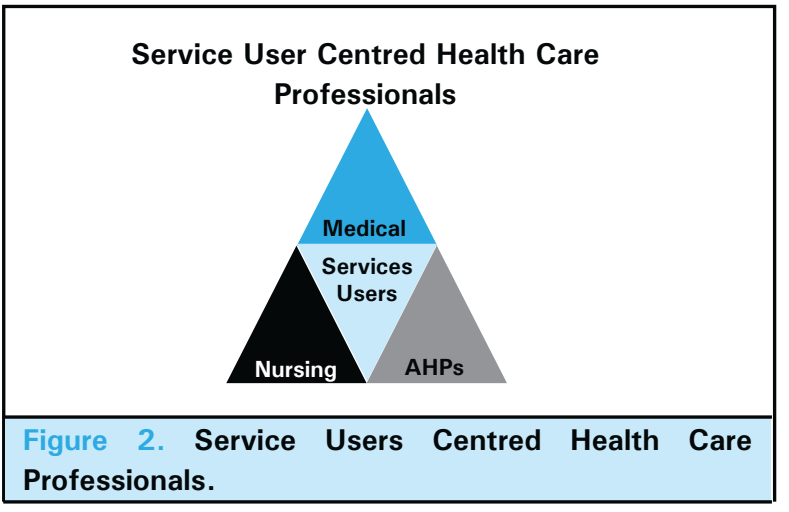

The relationship between health care professionals and service users has been characterised by a moral responsibility on the part of health care professionals. This requires health care professionals to treat service users fairly, equally and free from discrimination, ${ }^{23}$ to do the patient good, not knowingly wishing to harm service users and to respect service users' autonomy. ${ }^{24}$ Confidentiality and being honest are the results of these ethical beliefs.

\section{WAY FORWARD}

Many health care professionals express different views as to the service users' role in their autonomy and responsibility in interprofessional care. It is strongly felt that service users should have an active role in their health care and should be held more accountable and committed to facilitating care. The main theme that runs through all the above discussions is that of interprofessional team collaboration between service users and health care professionals, and among health 
Kaini. Service Users' Involvement and Engagement in Interprofessional Care

care professionals. Service users play a vital role to manage their own health, to shape the overall future of health care in their locality and to improve the quality of care by giving their opinion and feedback. It can be summarised that service users centred interprofessional team collaboration is very important to deliver effective health services.

Conflict of Interest: None.

\section{REFERENCES}

1. Payne M. Teamwork in Multiprofessional Care. New York: Palgrave; 2000.

2. Leathard A. Interprofessional Collaboration: From Policy to Practice in Health and Social Care. East Sussex: Routledge; 2003.

3. Colyer H. Responsibilities and accountabilities in interprofessional working, In: Koubel G, Bungay H (eds.) Rights, risks and responsibilities: Interprofessional working in health and social care. Basingstoke: Palgrave Macmillan; 2012.

4. WHO. Health Professionals Network (Online). [Cited 2016 February 10]; Available from: URL:http://www.who.int/ hrh/professionals/en/

5. Canadian Interprofessional Health Collaborative (CHIC). A National Interprofessional Competency Framework (Online). [Cited 2016 March 15]; Available from: URL:http:/ / www.cihc.ca/files/CIHC_IPCompetencies_Feb1210.pdf

6. Finch J. Interprofessional education and teamworking: a view from the education providers. British Medical Journal 2000; 321: p.1138-40.

7. Health Force Ontario (HFO). Interprofessional Care: A Blueprint for Action in Ontario, Interprofessional Care Project. Ontario: Health Force Ontario; 2007.

8. Buckland S, Hayes H, Ostrer C, Royle J, Steel R, Terpe M, Walton J, Yeeles P. Public Information Pack (PIP): How to get actively involved in NHS, public health and social care research (Online). [cited 2016 February 2016] ; Available from: URL:http://www.invo.org.uk/wp-content/ uploads/2011/12/PIP44jargonbuster.pdf

9. Health Force Ontario. Interprofessional Care: A Blueprint for Action in Ontario, Interprofessional Care Project. Ontario: Health Force Ontario; 2007.

10. House of Commons. Patient and public involvement in the NHS. London: HMSO; 2007.

11. Oandasan I, Robinson J. Final report of the interprofessional care strategic implementation committee (Online). [cited 2016 February 19]; Available from: URL:http://www. healthforceontario.ca/upload/en/whatishfo/ipcproject/ ccw g \% 20final $\% 20$ report $\% 20$ nov $\% 2020 \% 20$ - \% 20 final\%202010_.pdf

12. Postgraduate Medical Education Training Board in the United Kingdom. Patient's role in health care. London: PMETB; 2008.
13. Rankin J. Great Expectations, London: Institute of Public Policy Research; 2007.

14. Coney S. Effective Consumer Voice and Participation for New Zealand: A Systematic Review of the Evidence: Discussion Document. Auckland: New Zealand Guidelines Group; 2004

15. Hornby S, Atkins J. Collaborative Care: Interprofessional, Interagency and Interpersonal. Oxford: Blackwell Publishing: 2000

16. Reel K, Hutchings S. Being part of a team: Interprofessional care, In: Hawley G (ed.) Ethics in clinical practices: an interprofessional approach. Essex: Pearson Education. 2007; p.137-153.

17. Engel C, Gursky E. Management and interprofessional collaboration, In: Leathard A (ed.) Interprofessional collaboration: from policy to practice in health and social care. East Sussex: Routledge; 2003.

18. Manthorpe J. The perspectives of users and carers, In Leathard A (ed.) Interprofessional collaboration: from policy to practice in health and social care. East Sussex: Routledge; 2003.

19. Ridley J, Jones L. User and Public Involvement in Health Services: A Review (Online). [cited 2013 February 15]; Available from: URL:http://www.shstrust.org.uk/ downloads/pinc_litreview.pdf

20. Simces and Associates. Exploring the link between public involvement / citizen engagement and quality health care. A review and analysis of the current literature. Canada: Health Canada, Health Human Resources Strategies Division; 2003.

21. Gregory J. Conceptualising consumer engagement: A review of the literature. Working Paper 1 (Revised) (Online). [cited on 2016 February 3] Available from: URL:http://www. healthissuescentre.org.au/documents/items/2009/06/280 548-upload-00003.pdf

22. Morris $\mathrm{P}, \mathrm{O}^{\prime} \mathrm{Neill} F$. Preparing for patient-centred practice: developing the patient voice in health professional learning (Online). [cited 2016 February 17]. Available from: URL:http://www.leeds.ac.uk/medicine/meu/lifelong06/ papers/P_PennyMorris_FionaO'Neill.pdf

23. Department of Health. The NHS Constitution for England London: HMSO; 2012 . p.10.

24. Wall A. Some ethical issues arising from interprofessional working, In: A. Leathard A (ed.) Interprofessional collaboration: from policy to practice in health and social care. East Sussex: Routledge; 2003. 